\title{
Experimental methodology for tinplate rolling on a laboratory mill
}

\author{
Iryna Karmazina ${ }^{1}$, Volodymyr Kukhar ${ }^{1, *}$, Elena Balalayeva $^{1}$, Alla Larkina $^{2}$, and Valentina \\ Kashintseva ${ }^{3}$ \\ ${ }^{1}$ Pryazovskyi State Technical University, Universytetska str., 7, Mariupol, 87555, Ukraine \\ ${ }^{2}$ Samara State Technical University, Molodogvardeyskaya St., 194, Samara, 443100, Russia \\ ${ }^{3}$ Moscow State University of Civil Engineering, Yaroslavskoe shosse, 26, Moscow, 129337, Russia
}

\begin{abstract}
The review of cold rolling mills used for the production of tinplate and thin tinplate in the world is presented. World tinplate production is characterized by the desire to reduce the thickness of its steel base. In connection with the variety of tinplate rolling mills, peculiarities of the deformation conditions of thin tinplate, complexity of the technological process and theoretical prediction of the rolling process indices, especially in terms of the theoretical model universality, as well as paucity of existing practical data, the necessity of experimental research is substantiated. Experimental research methodology of energy and force modes for tinplate and thin tinplate rolling for different cold rolling mills: five-, six- and seven-stand, was developed. Deformation modes have been developed that allow simulating the process of continuous cold rolling of tinplate with a thickness of $0.16 \mathrm{~mm}$ and $0.28 \mathrm{~mm}$ in five-, six- and sevenstand mills, respectively. The technical characteristics of industriallaboratory equipment involved in experimental research are presented. The results of the chemical composition and mechanical properties investigation of the initial blank are presented. Experimental research of energy and force modes for tinplate rolling at different parameters of cold rolling mills using the developed methodology will determine their optimal combination, as well as justify the choice of rolling equipment in terms of energy efficiency of the rolling process and the quality of the strip.
\end{abstract}

\section{Introduction}

World tinplate production is characterized by the desire to reduce the thickness of its steel base [1], that along with high demands on mechanical properties, surface quality and accuracy of the geometric dimensions of the cold-rolled strip [2], presents a complex production task, also associated with the observance of certified production conditions and labor safety [3]. Recently, this task was solved by double rolling on rolling mills, as well as by the increase in the number of stands of continuous mills. The technical parameters change, the equipment modernization of the shops for the tinplate production, caused by the increasing requirements for it, have caused a variety of existing tinplate rolling mills:

\footnotetext{
* Corresponding author: kvv.mariupol@gmail.com
} 
continuous five-, six- and seven-stand; reversible two-stand. A suggestion to roll tinplate on a continuous seven-stand mill was put forward [4], the rationale for the feasibility of using such a mill was not revealed in the literature.

The peculiarity and complexity of the production technology of cold-rolled strips and tinplate are associated with intensive hardening, high rolling speed. Use of the metal ductility reserve can lead to crack formation [5-9], and high rolling speeds cause resonance vibrations that negatively affect the quality of the strip. These factors need to be taken into account when developing deformation modes and production technology.

Complicated conditions of tinplate rolling, the variety of tinplate rolling mills create difficulties both in the theoretical prediction of the indices of the rolling process, and in terms of experimental research, which explains their paucity. Among the latest works, the one [9], which authors experimentally researched the effect of tension on the rolling strength during cold strip deformation, should be mentioned. Due to the paucity of experimental research, it is important to assess the reliability of existing accepted theoretical solutions by experimental research of the parameters of the cold rolling process of thin tinplate, which could fully take into account technological process features and the difference in the properties of rolling equipment.

The review of the world tinplate production showed that currently continuous six-, fiveand four-stand mills are used for the single rolling; reverse two-stand are used to produce thin tinplate, also two-stand mills are used for double rolling (Fig. 1) [10]. The experience of the world practice shows that the thinner the essential thickness of the tinplate, the bigger the number of stands of the continuous mill of the primary rolling.

For example, a complex of producing a cold-rolled sheet and tinplate with the minimum thickness of $0.1 \mathrm{~mm}$ and maximum width of $1200 \mathrm{~mm}$ from "ThyssenKrupp Rasselstein GmbH" company [11], includes a continuous etching of hot-rolled strip plate, continuous six-stand cold rolling with the maximum possible rolling speed of $40.2 \mathrm{~m} / \mathrm{s}$ and annual capacity of 1.5 million tons, continuous cleaning strips, separation of bell-shaped and continuous annealing, two-stand rolling mill, strips of chromium plating, lacquering, varnishing, cutting, etc. Continuous six-stand cold rolling mill "ThyssenKrupp Rasselstein $\mathrm{GmbH}$ " is characterized by the following indices: capacity $-1.5 \mathrm{mln}$ tons/year; rolling speed - max. $2414 \mathrm{~m} / \mathrm{min}$; thickness of the hot-rolled strip - 1.0...4.0 mm; thickness of the cold strip - 0.1..1.2 mm; strip width $-700 \ldots 1400 \mathrm{~mm}$; coil diameter - max. $2800 \mathrm{~mm}$; coil weight - max. 46 tons; diameter of the work rolls $-565 \ldots 615 \mathrm{~mm}$; diameter of the back-up rolls $-1300 \ldots 1450 \mathrm{~mm}$. Rolling-tempering mill - respectively: thickness of the cold strip $-0.14 \ldots 0.55 \mathrm{~mm}$; strip width $-600 \ldots 1400 \mathrm{~mm}$; rolling speed - max. 2200 $\mathrm{m} / \mathrm{min}$; coil weight - max. 35 tons; diameter of the work rolls $-505 \ldots 563 \mathrm{~mm}$; diameter of the back-up rolls $-1270 \ldots 1420 \mathrm{~mm}$.

In Chiba (Japan) the production of tinplate sized of $(0.1 \ldots 1.0) \times(508 \ldots 1295) \mathrm{mm}$ has been adjusted. The complex for the tinplate production is represented by a unit of continuous etching of hot-rolled strip plate, a continuous five-stand cold rolling mill with a maximum rolling speed of $46.6 \mathrm{~m} / \mathrm{s}$ [11], separation of bell-shaped and continuous annealing, a two-stand rolling mill, lines of electrolytic tinning, varnishing, cutting, etc. Characteristics of a continuous five-stand cold rolling mill: the maximum possible rolling speed is $2800 \mathrm{~m} / \mathrm{min}$; diameter of work rolls $-495 \ldots 610 \mathrm{~mm}$; diameter of the back-up rolls is $1270 \ldots 1427 \mathrm{~mm}$.

Similar complexes of tinplate production equipment are located in South Korea and China. Thus, at the Dongbu Steel plant in Asan Bay (South Korea), tinplate is rolled up with a minimum thickness of steel up to $0.15 \mathrm{~mm}$, width of $600 \ldots 1000 \mathrm{~mm}$ (with a minimum thickness) in coils weighing up to 45 tons on a five-stand tandem (Fig. 2) [12] in a complex with a continuous etching and a two-stand mill of secondary rolling (Fig. 3) [13]. The five-stand tandem is equipped with 6-high stands, carousel reel, positive and negative 
work-roll and intermediate-roll bending systems, ESS (Enhanced Shifting System). Dongbu Steel stand-tandem has high capacity (design capacity - 1.34 million tons per year) and rolling speed (max. $1900 \mathrm{~m} / \mathrm{min})$.

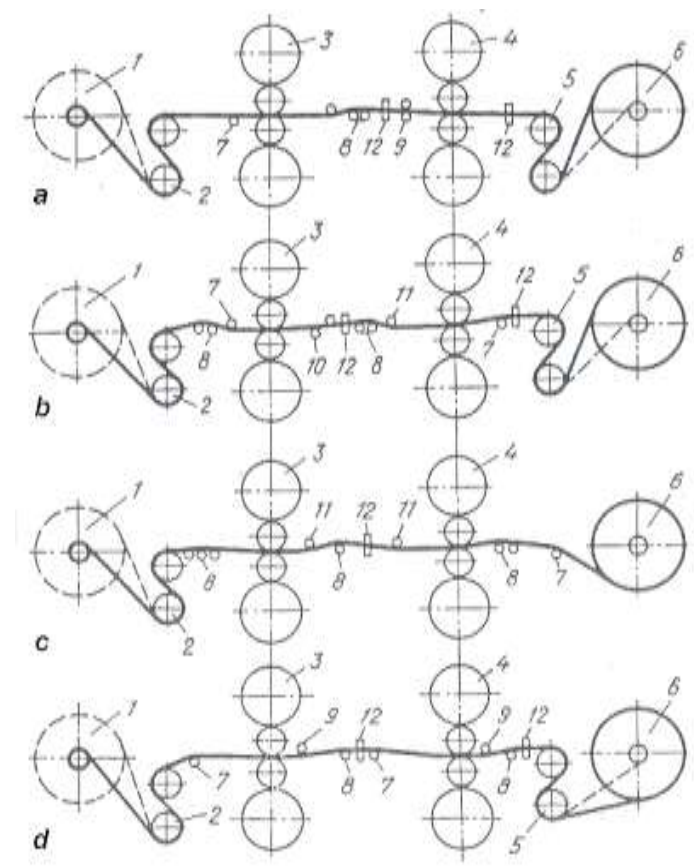

Fig. 1. Schemes of two-stand double reduction mill [10]: (a) 'Weirton Steel' mill, model 1320; (b) 'United States Steel' mill, model 1220; (c) 'Bethlehem Steel' mill 1220; (d) Karaganda Metallurgical Plant 1400 mill; (1) uncoiler; (2) front tension; (3) first work stand; (4) second work stand; (5) back tension; (6) reel; (7) deflection roll; (8) tensometric rolls; (9) drying rolls; (10), (11) accordingly up and down guide rolls; (12) thickness gauge.

The "Shougang Group Company" from West Beijing (China) has a complex of equipment for the tinplate production as part of a continuous five-stand tandem with the etching line (plant capacity of 1.8 million tons per year). The stand tandem also has a sixhigh stands, which allows the output of the minimum thickness of the cold-rolled strip -0.2 mm.

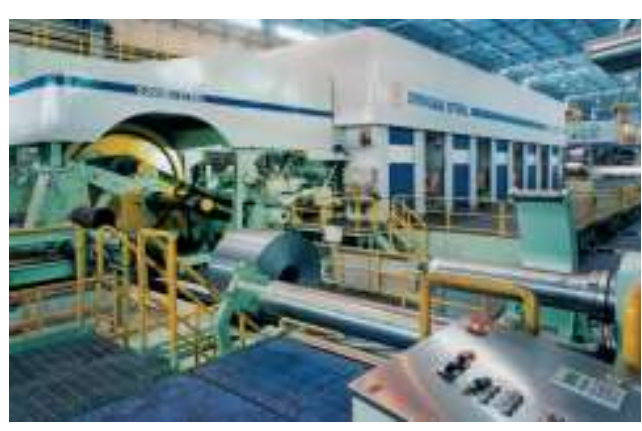

Fig. 2. Five-stand tandem rolling mill Dongbu Steel, Asan Bay [12].

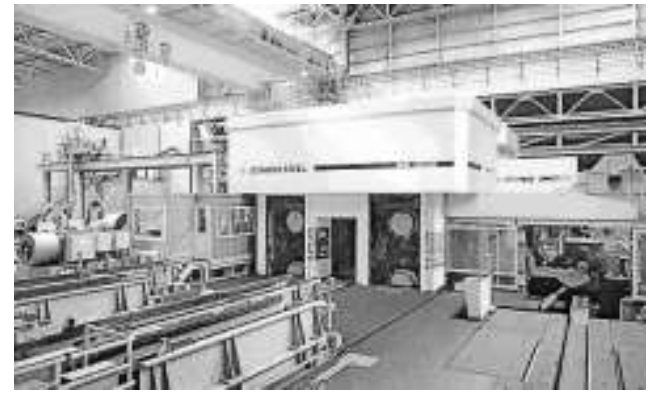

Fig. 3. A view of the double reduction mill Dongbu Steel, Asan Bay [13]. 
In Toyo (Japan), since 2000, four-stand continuous cold rolling mill combined with the etching line in an etching machine [14], with the ability to produce tinplate with the maximum thickness of $0.15 \mathrm{~mm}$, has operated. Getting such a small thickness of the tinplate on a four-stand mill became possible due to the use of six-high stands. Characteristics of a continuous four-stand cold rolling mill: strip thickness - 1.6...6.6 mm; coil diameter - max. $2100 \mathrm{~mm}$; coil weight - max. 25 tons; rolling speed - max. $1500 \mathrm{~m} / \mathrm{min}$; rolls diameter: 340/490/1300 mm; an individual drive from the AC motor.

In the CIS, a significant proportion of tinplate production is due to PJSC "Magnitogorsk Iron and Steel Works" (Russia) and JSC "Ispat-KarMet" (Kazakhstan). PJSC "Magnitogorsk Iron and Steel Works" does not have a technical capability of producing double reduced tinplate and produces single-reduced tinplate according to GOST 13345-85 (international standard) with a minimum thickness of $0.16 \mathrm{~mm}$ and a maximum width of $910 \mathrm{~mm}$ on a continuous five-stand cold rolling mill 1200 with an annual capacity of about 435,000 tons/year. The range of steel and tinplate, manufactured on a continuous six-stand cold rolling mill 1400 (capacity about 850,000 tons/year), "Ispat KarMet" (Kazakhstan), is limited to a thickness of $0.18 \mathrm{~mm}$ and a width of $936 \mathrm{~mm}$.

In Ukraine, all tinplate production is concentrated on PJSC "Zaporizhstal". The domestic producer still does not meet the needs for tinplate of Ukraine, not only in terms of volumes, but also in quality [15], it does not produce tinplate of the required sizes. The tinplate on PJSC "Zaporizhstal" is rolled on the equipment made in the 30's of the last century, which has insufficient capacity, high level of energy consumption [16]. The production is mainly done from pre-rolled products on the hot mill $[17,18]$.

Tinplate is produced in coils at a thickness of $0.22 ; 0.25 ; 0.28$ and $0.3 \mathrm{~mm}$. For a long time, it was produced with a maximum width of $321 \mathrm{~mm}$ and shipped to the consumer in sheets. The use of tinplate of such a small width on modern canning lines is impossible. Only in 2008 after the reconstruction the technology of producing tinplate with a width of $512 \mathrm{~mm}$ was mastered, which when cutting strips at a length of $712 \mathrm{~mm}$ allows customers to receive standard-size cards. Currently, the volume of the tinplate production of PJSC "Zaporizhstal" does not exceed 30-40 thousand tons/year. Therefore, the need for tinplate in Ukraine is covered by importing. However, Ukraine exports tinplate to Turkey, Moldova, Egypt, Syria, Jordan, and other countries.

There was a suggestion to use seven-stand mills with block construction of stands for tinplate rolling. There is no theoretical and technological justification for this suggestion yet.

The difference in the equipment of the shops of the tinplate production determines the development of process modes that correspond to the specific stand, production technologies - of the appropriate layout and configuration, and also creates difficulties in the theoretical prediction of the parameters of the rolling process, especially in terms of the universality of the theoretical model. An assessment of the validity of the theoretical decisions is the results of experimental studies. Many factors that influence the parameters when rolling the tinplate, associated with a significant complexity of the process, explain the difficulties in creating the conditions of the experiment and, as a result, the paucity of existing experimental research in this direction.

The purpose of the work is the development of the experimental research methodology for assessment of energy and force modes for tinplate rolling at different parameters of rolling equipment.

\section{Methods and Materials of Research}

The experimental research methodology was developed for the industrial-laboratory mill 300/260x250 of the Donbas State Engineering Academy; its general view is presented in Fig. 4. The industrial-laboratory mill includes the working stand and its main line, the 
equipment of which includes: electric motor DC-72 power of $85 \mathrm{~kW}$; gear clutch coupling; combined reduction-gear stand; universal spindles on the rolling bodies with a drive to the work rolls, which are characterized by high efficiency at high loads and angles of obliquity. The working stand of the mill $300 / 260 \times 250$ type with a four-high embodiment (quadro) with the nominal diameter and length of the barrel of drive work rolls $300 \mathrm{~mm}$ and $320 \mathrm{~mm}$, as well as with nominal diameter and length of barrel of the back-up rolls $260 \mathrm{~mm}$ and $250 \mathrm{~mm}$, respectively.
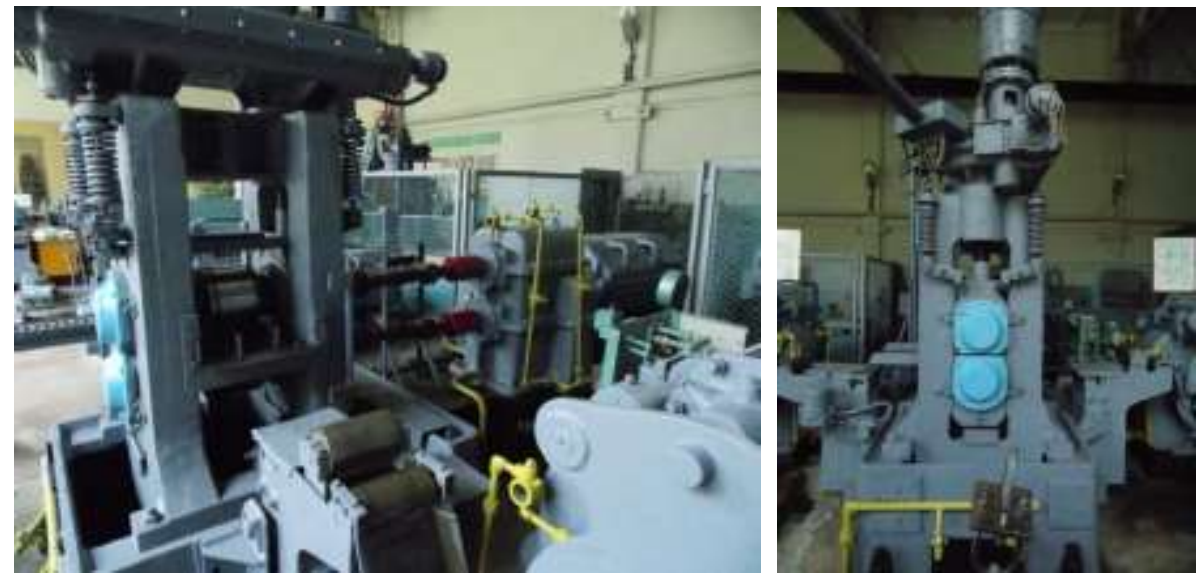

Fig. 4. General view of the work stand of the industrial-laboratory mill $300 / 260 \times 250$ of the Donbas State Engineering Academy (Ukraine).

The rolling block is equipped with a mechanism of balancing and work rolls banding, made in the form of plunger cylinders. The roll space is adjusted to the required value and is regulated during the rolling process with the help of an electromechanical push mechanism, driven by two electric DC motors P-41 with a power of $1.5 \mathrm{~kW}$ through a twostage worm gear reductor and a screw-nut transmission. The mill 300/260x200 is equipped with the dynamometers (Fig. 5) for fixing the rolling strength. They are made in the form of ring elastic elements with the strain gauges of the resistance glued on them and installed directly under the push screws.

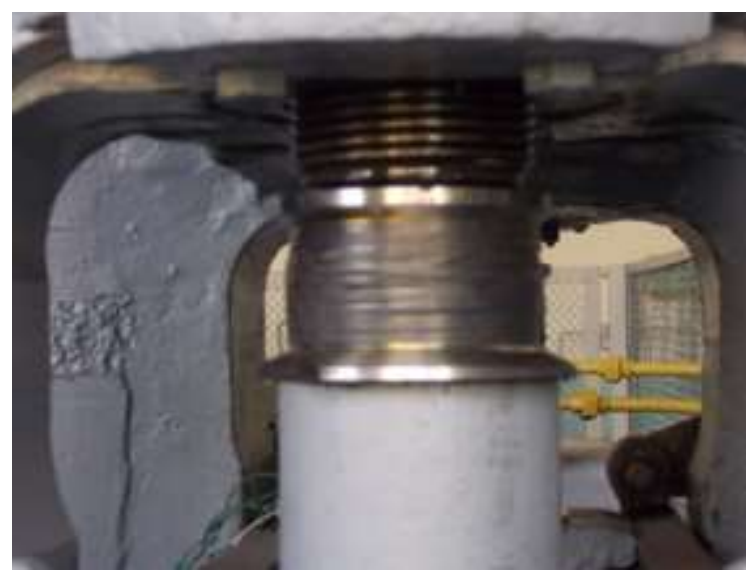

Fig. 5. General view of the dynamometers of the industrial-laboratory mill 300/260×200. 
Since the rolling mill $300 / 260 \times 250$ is one-stand and the full simulation of continuous rolling of strips cannot be performed it was decided to make samples for sheet rolling which corresponds to continuous one with the same values of front and back tension. The samples were made from a hot-rolled sheet of the thickness of steel of $2 \mathrm{~mm}$ of the make $08 \mathrm{kp}$ (GOST 1050, the chemical composition is investigated later and is given in Table 1), rolled on Hot Strip Rolling Mill (HSRM) 1700 PJSC "Illich Iron and Steel Works of Mariupol" (Ukraine) and taken from the middle of a pack of pre-oiled sheets, which eliminated the presence of oxides and contaminants on its surface. Cutting of the sheet on stripes $40 \mathrm{~mm}$ in width and $325 \mathrm{~mm}$ in length is carried out by hydraulic guillotine scissors. The choice of sample size is due to the strength and design constraints of the mill $300 / 260 \times 250$, as well as the requirements for the sizes of samples for mechanical tests. After cutting, the ready samples were put up in piles and wrapped with the film for the period of storage.

Table 1: Chemical composition and mechanical properties of the initial blank

\begin{tabular}{|c|c|c|}
\hline \multirow{8}{*}{$\begin{array}{l}\text { Mass fraction } \\
\text { of elements, \% }\end{array}$} & $\mathrm{C}$ & 0.05 \\
\hline & $\mathbf{S i}$ & $<0.01$ \\
\hline & Mn & 0.33 \\
\hline & $\mathbf{N i}$ & 0.02 \\
\hline & $\mathbf{S}$ & 0.016 \\
\hline & $\mathbf{P}$ & 0.013 \\
\hline & $\mathrm{Cr}$ & 0.03 \\
\hline & $\mathbf{C u}$ & 0.04 \\
\hline \multicolumn{2}{|l|}{ Yield Stress $\left(\sigma_{\mathrm{s}}\right), \mathrm{MPa}$} & 285 \\
\hline \multicolumn{2}{|l|}{ Rockwell Hardness, HRB } & 49 \\
\hline \multicolumn{2}{|l|}{ Relative elongation $(\delta), \%$} & 27 \\
\hline
\end{tabular}

The research of the chemical composition of the steel of initial blanks was carried out on the equipment of the central laboratory of PJSC "Azovstal" Iron and Steel Works" (Mariupol, Ukraine). The research of the yield strength of the initial blanks was carried out in the conditions of the central laboratory of PJSC "Illich Iron and Steel Works of Mariupol" with the use of equipment: ZDM (Zyklische Dehnung Maschine, German) (Fig. 6) to determine the yield and strength, in addition a device of type TKS-1 (hardness tester with SuperRockwell cone) (Fig. 7) - to determine hardness. The TKS-1 desktop type is intended for determining the surface hardness of metals by the method of pushing a diamond cone or a steel ball under the action of a given load for a certain time. The results of the study of the initial blanks are presented in Table 1. 


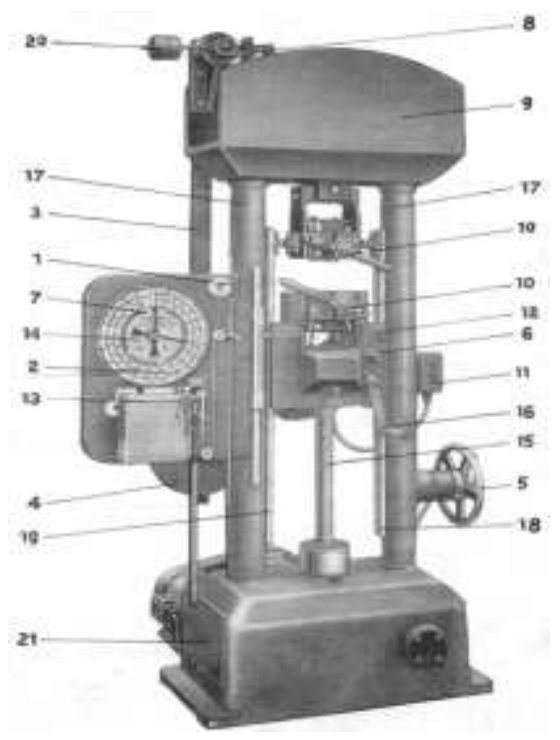

Fig. 6. ZDM: (1) recorder pinion drive for the recording of the diagram "load-deformation"; (2) sliding ruler for elongation measuring; (3) strength generating lever; (4) additional weights with knurling nuts; (5) flywheel of the variator; (6) shift knob (main, high-speed and manual driving mechanism); (7) power meter dial; (8) oil brakes; (9) crossbar; (10) the head of the quick-acting device (wedge roller clamps); (11) button station; (12) slider; (13) roll for driving strip; (14) arrow with forced movement; (15) spindle; (16) year chamber of a manual drive mechanism; (17) bed stands; (18) wheel slides; (19) base - lower part of the bed; (20) adjustable weights; (21) protection that prevents the accidental twisting of the strength measuring device from the correct position.

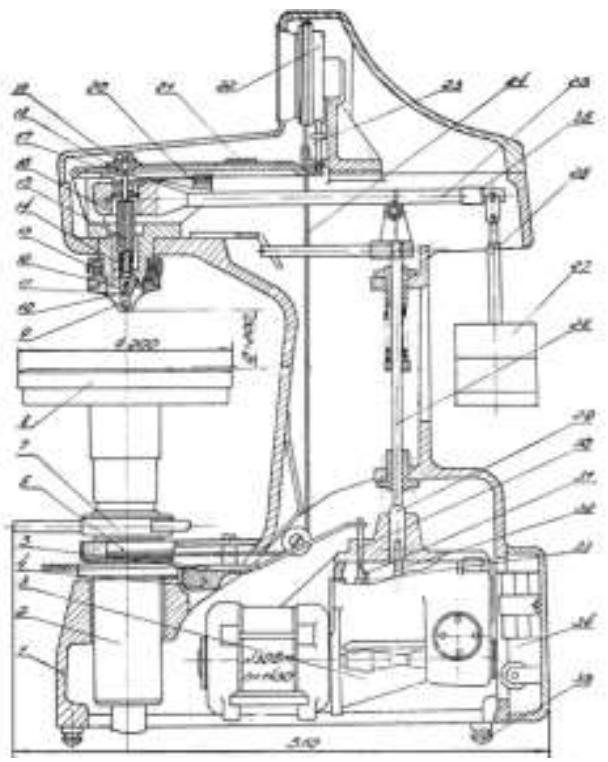

Fig. 7. Hardness tester devise TKS-1: (1) body; (2) lifting mechanism; (3) device drive; (4) button; (5) extension; (6) drum; (7) flywheel; (8) table; (9) mandrel; (10) screw; (11) limiter; (12) guide sleeve; (13) clip; (14) spring; (15) spindle; (16) lever block; (17) floating suspension; (18) strap; (19) screw; (20) measuring lever; (21) weight; (22) indicator; (23) tip; (24) cable; (25) cargo lever; (26) suspension; (27) cargoes; (28) rod; (29) pusher; (30) bolt; (31) latch; (32) cam; (33) retched wheel; (34) panel; (35) support; (36) cargo. 


\section{Result of research}

In the development of reducing (process) modes, the recommendations of Ya.D. Vasilev, set forth in the paper [19], were guided by. The author notes that at domestic and foreign cold rolling mills, the distribution of squeezing by stands is carried out according to the schemes presented in Fig. 8

Scheme "a", presented in Fig. 8 is recommended to use when rolling relatively thick strips, as well as when rolling thin strips with the minimum polythickness [19]. Scheme "c", presented in Fig. 8, is recommended to use with considerable longitudinal polythickness of the strip [19]. According to the schemes "b", "d", "e", represented in Fig. 8, the reduction for the continuous cold rolling mills is set to be almost identical, except for the first (Fig. 8, "b") and the last stands (Fig. 8, "d", "e"). The use of higher reduction in the last stand of a continuous mill (Fig. 8, "d") allows to increase the thickness of the strip in the last interstand space which helps to reduce the strip breaks (ruptures). Such a scheme is used for the rolling of thin tinplate [19]. Increasing the reduction in the last stand of a continuous mill leads to an increase in the load of the mechanical and electrical equipment of the stand, in such case it is necessary to reduce the speed or compensation in the last stand, as shown in the diagram "e", Fig. 8. It is implemented at insufficient power of the reel or using the notched surface of rolls [19].

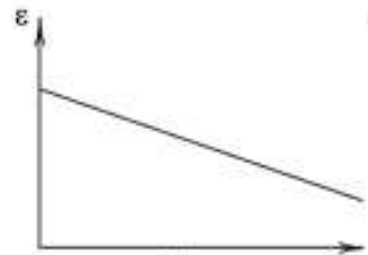

(a)

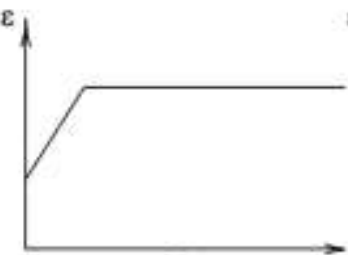

(b)

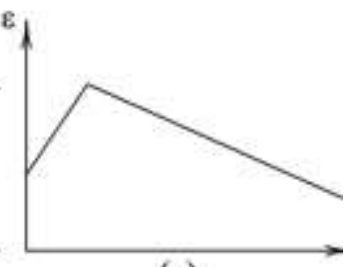

(c)

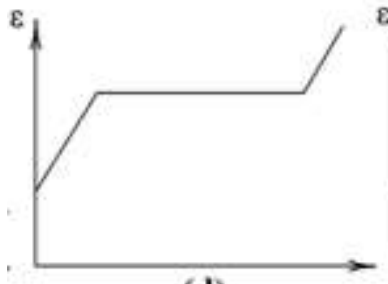

(d)

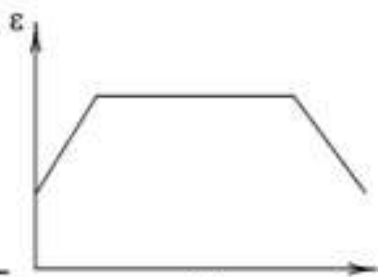

(e)

Fig. 8. Schemes of the distribution of compensation in the stands of the continuous cold rolling mill [19].

Based on the above-mentioned recommendations, process modes have been developed (Table 2-13), which allow to simulate the process of continuous cold rolling of tinplate with thicknesses of $0.16 \mathrm{~mm}$ and $0.28 \mathrm{~mm}$ in the five-, six-, and seven-stand, respectively. Process modes are developed on the basis of operation experience of modern continuous cold rolling mills of tinplate and on condition of even loading of stands by strength and moment of rolling, and also in accordance with recommendations [20], according to which the choice of compensation for the first and last stands of a mill is of great importance. The amount of reduction in the first stand contributes to reducing the initial polythickness of the strip and its surface defects. With a slight back stretching (practically in its absence, as in the case of an experiment), in order to avoid shifting the strip along the axis of rolling compensation in the first stand it is recommended to set within $30 \%$. The amount of 
reduction in the last stand of a continuous mill affects the effectiveness of the systems of automatic adjustment of thickness, tension, shape of the strip and should be highest possible.

The character of the distribution of compensation in the stands of a continuous mill in the process modes, presented in tables $2-7$, corresponds to the scheme commonly used for rolling thin tinplate [19]. Distribution of compensation in the stands of a continuous mill in the process modes, presented in the tables 8-13, has a growing character, when the reduction increases from the first stand of the continuous mill to the last, which ensures rolling of the increased thickness of the strip, which has a large margin of plasticity.

The deformations, established for the last stand of the developed modes, are practically equal to the deformations of the previous stand, which does not conform to the conventional recommendations, but it explained by rolling of already riveted strips in a particular stand of the laboratory-industrial mill, the rolling strength would exceed the permissible value.

Table 2. Mode of conventional deformation for modeling of the tinplate rolling process with the thickness of $0.16 \mathrm{~mm}$ on the five-stand mill

\begin{tabular}{c|c|c|c|c|c}
\hline \multirow{2}{*}{ Index } & \multicolumn{5}{|c}{ Number of pass } \\
\cline { 2 - 6 } & $\mathbf{1}$ & $\mathbf{2}$ & $\mathbf{3}$ & $\mathbf{4}$ & $\mathbf{5}$ \\
\hline $\mathrm{h}_{\mathrm{i}-1, \mathrm{~mm}}$ & 2.00 & 1.44 & 0.84 & 0.48 & 0.28 \\
$\mathrm{~h}_{\mathrm{i}, \mathrm{mm}}$ & 1.44 & 0.84 & 0.48 & 0.28 & 0.16 \\
$\varepsilon, \%$ & 28.00 & 42.00 & 42.00 & 42.00 & 43.00 \\
$\sum \varepsilon, \%$ & 28.00 & 58.00 & 76.00 & 86.00 & 92.00 \\
\hline
\end{tabular}

Table 3. Mode of conventional deformation for modeling of the tinplate rolling process with the thickness of $0.16 \mathrm{~mm}$ on the six-stand mill

\begin{tabular}{c|c|c|c|c|c}
\hline \multirow{2}{*}{ Index } & \multicolumn{5}{|c}{ Number of pass } \\
\cline { 2 - 6 } & 1 & 2 & 3 & 4 & 5 \\
\hline $\mathrm{h}_{\mathrm{i}-1, \mathrm{~mm}}$ & 2.00 & 1.40 & 0.91 & 0.59 & 0.38 \\
$\mathrm{~h}_{\mathrm{i}, \mathrm{mm}}$ & 1.40 & 0.91 & 0.59 & 0.38 & 0.25 \\
$\varepsilon, \%$ & 30.00 & 35.00 & 35.00 & 35.00 & 35.00 \\
$\sum \varepsilon, \%$ & 30.00 & 55.00 & 70.00 & 81.00 & 88.00 \\
\hline
\end{tabular}

Table 4. Mode of conventional deformation for modeling of the tinplate rolling process with the thickness of $0.16 \mathrm{~mm}$ on the seven-stand mill

\begin{tabular}{c|c|c|c|c|c}
\hline \multirow{2}{*}{ Index } & \multicolumn{5}{|c}{ Number of pass } \\
\cline { 2 - 6 } & 1 & 2 & 3 & 4 & 5 \\
\hline $\mathrm{h}_{\mathrm{i}-1, \mathrm{~mm}}$ & 2.00 & 1.66 & 1.13 & 0.77 & 0.52 \\
$\mathrm{~h}_{\mathrm{i}, \mathrm{mm}}$ & 1.66 & 1.13 & 0.77 & 0.52 & 0.35 \\
$\varepsilon, \%$ & 17.00 & 32.00 & 32.00 & 32.00 & 32.00 \\
$\sum \varepsilon, \%$ & 17.00 & 44.00 & 62.00 & 74.00 & 82.00 \\
\hline
\end{tabular}

Table 5. Mode of conventional deformation for modeling of the tinplate rolling process with the thickness of $0.28 \mathrm{~mm}$ on the five-stand mill

\begin{tabular}{c|c|c|c|c|c}
\hline \multirow{2}{*}{ Index } & \multicolumn{5}{|c}{ Number of pass } \\
\cline { 2 - 6 } & 1 & 2 & 3 & 4 & 5 \\
\hline $\mathrm{h}_{\mathrm{i}-1}, \mathrm{~mm}$ & 2.00 & 1.42 & 0.95 & 0.64 & 0.43 \\
$\mathrm{~h}_{\mathrm{i}, \mathrm{mm}}$ & 1.42 & 0.95 & 0.64 & 0.43 & 0.28 \\
$\varepsilon, \%$ & 29.00 & 33.00 & 33.00 & 33.00 & 34.00 \\
$\sum \varepsilon, \%$ & 29.00 & 52.00 & 68.00 & 79.00 & 86.00 \\
\hline
\end{tabular}


Table 6. Mode of conventional deformation for modeling of the tinplate rolling process with the thickness of $0.28 \mathrm{~mm}$ on the six-stand mill

\begin{tabular}{c|c|c|c|c|c}
\hline \multirow{2}{*}{ Index } & \multicolumn{5}{|c}{ Number of pass } \\
\cline { 2 - 6 } & 1 & 2 & 3 & 4 & 5 \\
\hline $\mathrm{h}_{\mathrm{i}-1, \mathrm{~mm}}$ & 2.00 & 1.57 & 1.12 & 0.79 & 0.56 \\
$\mathrm{~h}_{\mathrm{i}, \mathrm{mm}}$ & 1.57 & 1.12 & 0.79 & 0.56 & 0.40 \\
$\varepsilon, \%$ & 21.00 & 29.00 & 29.00 & 29.00 & 29.00 \\
$\sum \varepsilon, \%$ & 21.00 & 44.00 & 60.00 & 72.00 & 80.00 \\
\hline
\end{tabular}

Table 7. Mode of conventional deformation for modeling of the tinplate rolling process with the thickness of $0.28 \mathrm{~mm}$ on the seven-stand mill

\begin{tabular}{c|c|c|c|c|c}
\hline \multirow{2}{*}{ Index } & \multicolumn{5}{|c}{ Number of pass } \\
\cline { 2 - 6 } & 1 & 2 & 3 & 4 & 5 \\
\hline $\mathrm{h}_{\mathrm{i}-1}, \mathrm{~mm}$ & 2.00 & 1.59 & 1.19 & 0.90 & 0.67 \\
$\mathrm{~h}_{\mathrm{i}}, \mathrm{mm}$ & 1.59 & 1.19 & 0.90 & 0.67 & 0.50 \\
$\varepsilon, \%$ & 20.00 & 25.00 & 25.00 & 25.00 & 25.00 \\
$\sum \varepsilon, \%$ & 20.00 & 40.00 & 55.00 & 66.00 & 75.00 \\
\hline
\end{tabular}

Table 8. Mode of the growing deformations for modeling of the tinplate rolling process with the thickness of $0.16 \mathrm{~mm}$ on the five-stand mill

\begin{tabular}{c|c|c|c|c|c}
\hline \multirow{2}{*}{ Index } & \multicolumn{5}{|c}{ Number of pass } \\
\cline { 2 - 6 } & 1 & 2 & 3 & 4 & 5 \\
\hline $\mathrm{h}_{\mathrm{i}-1}, \mathrm{~mm}$ & 2.00 & 1.40 & 0.91 & 0.59 & 0.33 \\
$\mathrm{~h}_{\mathrm{i}}, \mathrm{mm}$ & 1.4 & 0.91 & 0.59 & 0.33 & 0.16 \\
$\varepsilon, \%$ & 30.00 & 35.00 & 35.00 & 45.00 & 50.00 \\
$\sum \varepsilon, \%$ & 30.00 & 55.00 & 70.00 & 84.00 & 92.00 \\
\hline
\end{tabular}

Table 9. Mode of the growing deformations for modeling of the tinplate rolling process with the thickness of $0.16 \mathrm{~mm}$ on the six-stand mill

\begin{tabular}{c|c|c|c|c|c}
\hline \multirow{2}{*}{ Index } & \multicolumn{5}{|c}{ Number of pass } \\
\cline { 2 - 6 } & 1 & 2 & 3 & 4 & 5 \\
\hline $\mathrm{h}_{\mathrm{i}-1}, \mathrm{~mm}$ & 2.00 & 1.80 & 1.40 & 1.00 & 0.60 \\
$\mathrm{~h}_{\mathrm{i}}, \mathrm{mm}$ & 1.80 & 1.40 & 1.00 & 0.60 & 0.32 \\
$\varepsilon, \%$ & 10.00 & 22.00 & 29.00 & 40.00 & 47.00 \\
$\sum \varepsilon, \%$ & 10.00 & 30.00 & 50.00 & 70.00 & 84.00 \\
\hline
\end{tabular}

Table 10. Mode of the growing deformations for modeling of the tinplate rolling process with the thickness of $0.16 \mathrm{~mm}$ on the seven-stand mill

\begin{tabular}{c|c|c|c|c|c}
\hline \multirow{2}{*}{ Index } & \multicolumn{5}{|c}{ Number of pass } \\
\cline { 2 - 6 } & 1 & 2 & 3 & 4 & 5 \\
\hline $\mathrm{h}_{\mathrm{i}-1}, \mathrm{~mm}$ & 2.00 & 1.60 & 1.28 & 1.00 & 0.72 \\
$\mathrm{~h}_{\mathrm{i}}, \mathrm{mm}$ & 1.60 & 1.28 & 1.00 & 0.72 & 0.47 \\
$\varepsilon, \%$ & 20.00 & 21.00 & 22.00 & 28.00 & 35.00 \\
$\sum \varepsilon, \%$ & 20.00 & 36.00 & 50.00 & 64.00 & 77.00 \\
\hline
\end{tabular}


Table 11. Mode of the growing deformations for modeling of the tinplate rolling process with the thickness of $0.28 \mathrm{~mm}$ on the five-stand mill

\begin{tabular}{c|c|c|c|c|c}
\hline \multirow{2}{*}{ Index } & \multicolumn{5}{|c}{ Number of pass } \\
\cline { 2 - 6 } & 1 & 2 & 3 & 4 & 5 \\
\hline $\mathrm{h}_{\mathrm{i}-1, \mathrm{~mm}}$ & 2.00 & 1.54 & 1.12 & 0.76 & 0.48 \\
$\mathrm{~h}_{\mathrm{h}, \mathrm{mm}}$ & 1.54 & 1.12 & 0.76 & 0.48 & 0.28 \\
$\varepsilon, \%$ & 23.00 & 27.00 & 32.00 & 37.00 & 41.80 \\
$\sum \varepsilon, \%$ & 23.00 & 44.00 & 62.00 & 76.00 & 86.00 \\
\hline
\end{tabular}

Table 12. Mode of the growing deformations for modeling of the tinplate rolling process with the thickness of $0.28 \mathrm{~mm}$ on the six-stand mill

\begin{tabular}{c|c|c|c|c|c}
\hline \multirow{2}{*}{ Index } & \multicolumn{5}{|c}{ Number of pass } \\
\cline { 2 - 6 } & 1 & 2 & 3 & 4 & 5 \\
\hline $\mathrm{h}_{\mathrm{i}-1}, \mathrm{~mm}$ & 2.00 & 1.60 & 1.22 & 0.88 & 0.61 \\
$\mathrm{~h}_{\mathrm{i}}, \mathrm{mm}$ & 1.60 & 1.22 & 0.88 & 0.61 & 0.42 \\
$\varepsilon, \%$ & 20.00 & 24.00 & 28.00 & 30.00 & 32.00 \\
$\sum \varepsilon, \%$ & 20.00 & 39.00 & 56.00 & 69.00 & 79.00 \\
\hline
\end{tabular}

Table 13. Mode of the growing deformations for modeling of the tinplate rolling process with the thickness of $0.28 \mathrm{~mm}$ on the seven-stand mill

\begin{tabular}{c|c|c|c|c|c}
\hline \multirow{2}{*}{ Index } & \multicolumn{5}{|c}{ Number of pass } \\
\cline { 2 - 6 } & 1 & 2 & 3 & 4 & 5 \\
\hline $\mathrm{h}_{\mathrm{i}-1}, \mathrm{~mm}$ & 2.00 & 1.60 & 1.25 & 0.96 & 0.72 \\
$\mathrm{~h}_{\mathrm{i}}, \mathrm{mm}$ & 1.60 & 1.25 & 0.96 & 0.72 & 0.53 \\
$\varepsilon, \%$ & 20.00 & 22.00 & 23.00 & 25.00 & 26.00 \\
$\sum \varepsilon, \%$ & 20.00 & 38.00 & 52.00 & 64.00 & 73.00 \\
\hline
\end{tabular}

For the above-mentioned process modes, schemes simulating the process of rolling tinplate in a five-, six-, and seven-kilowatts continuous state have been developed.

As lubricant, palm oil is used, which is brought to the strip before the task in the rolls of the mill.

Recording in time of the current values of rolling power is carried out using light oscilloscopes H-145, except for which the corresponding measuring chains include DC power supply AGAT and strain gauge TOPAZ-3-01. In addition, the recording of the value of the rolling strength is made and using a computer with an integrated analog-to-digital converter ADC16-32, which ensures the ability to measure in sixteen differentiated channels. The input signal in this case is digitized by a converter with a frequency up to 100 $\mathrm{kHz}$ with the ability to amplify in the range $1 \ldots 1000$. The calibration of the measuring devices of the rolling strength is carried out on the press by its loading by strengths of known size and obtaining the corresponding oscillograms.

\section{Discussion}

The difference in the composition of the equipment of shops for the tinplate production, the indices of the tinplate rolling mills, the peculiarity of the conditions of the deformation of thin tinplate the complexity of theoretical prediction and experimental determination of the parameters of the rolling process.

The necessity of carrying out of experimental research on determination of powersupply parameters at rolling of tinplate under various parameters of cold rolling mills is substantiated. 
The methodology of experimental research energy and power modes for tinplate and thin tinplate rolling for different rolling mills: five-, six-, seven-stand was developed.

Experimental research of energy and power modes for tinplate rolling at different parameters of cold rolling mills using the developed methodology will determine their optimal combination, as well as justify the choice of rolling equipment in terms of energy efficiency of the rolling process and the quality of the strip.

The authors honor the bright memory of Professor Yuriy V. Konovalov (October 9, 1931 - January 19, 2016), who was the inspiration for this work. Besides, the research was carried out in accordance with the fundamental project No.0117U002269, which is performed at the expense of the general fund of the State budget of Ukraine on the topic "Development of scientific and technological bases for the production of high quality metal products from sheet and special-purpose composites".

\section{References}

1. Yu. V. Konovalov, A. G. Prysiazhnyi, I. V. Karmazina, "Analysis of trends development tinplate world production", Metal and Casting of Ukraine, 1, pp. 3-6 (in Russian) (2015)

2. Ya. D. Vasilev, A. Yu. Putnoki, O. V. Simenenko, "Modern cold rolling mill to the plant "Zaporizhstal", Metallurgical and Mining Industry, 1, pp. 37-40, (in Russian) (2007),

3. V. Kukhar, N. Yelistratova, V. Burko, Yu. Nizhelska, O. Aksionova, "Estimation of occupation safety risks at energetic sector of Iron and Steel Works", International Journal of Engineering \& Technology (UAE), Vol. 7, No.2.23, pp.216-220 (2018) https://doi.org/10.14419/ijet.v7i2.23.11922

4. V. I. Kaplanov, A. G. Prysiazhnij, N. V. Lepors'ka, O. V. Kaplanova, O. V. Shemyakin, A. V. Vasekin, Pat. 201005396, Multistand continuous cold rolling mill of thin strips and tinplate (in Ukrainianian) (Ukraine, 2010)

5. M. Černík, R. Gburík, L. Hrabčáková, P. Vranec, "Texture analysis of tinplate steel and its application in production of double reduced high strength tinplate grades with controlled earing properties", IOP Conference Series: Materials Science and Engineering, Vol. 82, Conf. 1, pp. 012108 (2015)

6. E. Balalayeva, V. Artiukh, V. Kukhar, O. Tuzenko, V. Glazko, A. Prysiazhnyi, V. Kankhva, "Researching of the Stress-Strain State of the Open-Type Press Frame Using of Elastic Compensator of Errors of "Press-Die" System", Advances in Intelligent Systems and Computing, Springer, Vol.692, pp. 220-235 (2018) https://doi.org/10.1007/978-3-319-70987-1_24

7. A. V. Grushko, V. V. Kukhar, Yu. O. Slobodyanyuk, "Phenomenological Model of Low-Carbon Steels Hardening during Multistage Drawing", Solid State Phenomena, Vol. 265, pp. 114-123 (2017) https://doi.org/10.4028/www.scientific.net/SSP.265.114

8. V. A. Fedorinov, A. M. Spasskaya, N. A. Zakorvashevich, N. A. Koryachenko, "Mathematical design of degree of the use of supply of plasticity on edges at coldrolled ribbon and strip", Materials Working by Pressure, Vol. 1, pp. 81-84 (in Russian) (2011)

9. Ya. D. Vasilev, D. N. Samokish, R. A. Zamogil'nyj, D. V. Zheleznov "Experimental study of the effect of tension on rolling force curves and plasticity in cold rolling", Materials Working by Pressure, 1(44), pp. 192-198 (in Russian) (2017)

10. Ya. D. Vasilev, A. V. Dementienko, S. G. Gorbunkov, "Tinplate production by double rolling”, 125 p., (in Russian) (Moscow, Metallurgy, 1994) 
11. M. Tsujimoto, T. Kaneko, Y. Yamada, et al., "Technological development of high speed (2800 mpm) cold rolling”, CAMP-ISIJ, 15, pp. 317-320 (2002)

12. https:/www.sms-group.com/sms-group/downloads/ download-detail/22677/ (Last accessed 04.03.2019)

13. Y. H. Lee, B. I. Roh, W. I. Chun, K. Aeberli, H. J. Pohl, "Two-stand temper and double reduction mill at Dongbu Steel, Asan Bay Works", Revue de Métallurgie, 97(11), pp. 1391-1398 (2000)

14. A. Hiraiwa, S. Nouchi, M. Toshinori, et al., "New tandem cold rolling mill at Toyo Works", CAMP-ISIJ, 15, pp. 321-323 (2002)

15. T. Lagoda, E. Derevyanko, "Zhizn moya - zhestyanka [My life is tin]", Business, Vol. 34 (353), pp. 110-113 (in Russian) (2003)

16. Ya. D. Vasilev, A. Yu. Putnoki, O. V. Simenenko, "The Concept of the Development of the rolling production of the "Zaporozhstal" plant", Metallurgical and Mining Industry, 2, pp. 48-51 (in Russian) (2006)

17. V. Kukhar, A. Prysiazhnyi, E. Balalayeva, O. Anishchenko, "Designing of induction heaters for the edges of pre-rolled wide ultrafine sheets and strips correlated with the chilling end-effect", Modern Electrical and Energy System MEES'2017, IEEE, Kremenchuk, November 15-17, pp. 404-407 (Ukraine, Kremenchuk Mykhailo Ostrohradskyi National University, 2017) https://doi.org/10.1109/MEES.2017.8248945

18. V. Kukhar, O. Kurpe, E. Klimov, E. Balalayeva, V. Dragobetskii, "Improvement of the Method for Calculation the Metal Temperature Loss on a Coilbox Unit at the Rolling on Hot Strip Mills", International Journal of Engineering \& Technology (UAE), 7(4.3), pp. 35-39 (2018) https://doi.org/10.14419/ijet.v7i4.3.19548

19. Ya. D. Vasilev, "Engineering models and algorithms for calculating the parameters of the cold rolling", 368 p. (in Russian) (Moscow, Metallurgy, 1995)

20. A. F. Pimenov, O. N. Soskovets, A. I. Traino, V. L. Traino, N. P. Netyosov, "Cold rolling and finish tinplate” 208 p. (in Russian) (Moscow, Metallurgy, 1990) 